\title{
A Gain Scheduled Method for Speed Control of Wind Driven Doubly Fed Induction Generator
}

\author{
Wei Wang, Kang-Zhi Liu, Tadanao Zanma \\ Dept. of Electrical and Electronics Engineering, Chiba University, Chiba, Japan \\ Email: kzliu@faculty.chiba-u.jp
}

Received 2013

\begin{abstract}
This paper proposes a gain scheduled control method for a doubly fed induction generator driven by a wind turbine. The purpose is to design a variable speed control system so as to extract the maximum power in the region below the rated wind speed. Gain scheduled control approach is applied in order to achieve high performance over a wide range of wind speed. A double loop configuration is adopted. In the inner loop, the rotor speed is used as the scheduling parameter, while a function of wind and rotor speed is used as the scheduling parameter in the outer loop. It is verified in simulations that a high tracking performance has been achieved.
\end{abstract}

Keywords: Doubly fed induction generator, Gain scheduled control method, speed control, current control

\section{Introduction}

With rapid development of modern industries, fossil fuels are being exhausted and environment is being destroyed seriously. For instance, burning of fossil fuels generates much waste carbon dioxide and causes global warming. As a solution to shortage of fossil fuels and environmental problems, much attention has been paid to the wind energy utilization because the wind energy is inexhaustible and has no emission of carbon dioxide and radioactive waste.

However, the wind energy is heavily influenced by weather and varies irregularly. Since the power captured by the wind turbine is proportional to the swept area and the cube of the wind speed, the utilization efficiency of wind power system becomes more and more important.

In wind farms, doubly fed induction generator (DFIG) based doubly fed system and permanent magnet generator (PMSG) based direct-drive system are generally installed. Since DFIG is advantageous in lower cost and low power loss caused by power electronics device, it is widely used. As shown in Fig 1, DFIG system is different from conventional wind power system in that its stator is directly connected to the grid and the rotor is connected to the grid through a back-to-back converter [1].

However, it is hard for the conventional linear control method to achieve high performance of DFIG systems in the case of large wind speed variation because of the high nonlinearity of wind power. So in recent years, non-

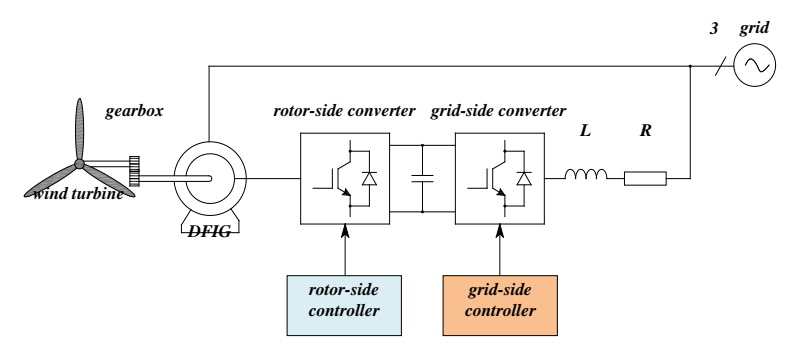

Fig 1: Block diagram of DFIG system.

linear control methods have been studied in order to improve the performance of DFIG. For example, [7] applied the sliding-mode control to the direct active and reactive power regulation of DFIG. In [8] the exact linearization method is applied to the transient stability control of DFIG in face of fault. [9] proposed a combination of PI control and state feedback nonlinear control so as to improve the dynamic behavior after clearing the fault.

In this paper, a gain scheduled method is proposed aiming at high performance in variable speed control which is indispensable in the maximum power point tracking. To this end, the nonlinear model of DFIG system will be transformed equivalently as an LPV model first. Then, a gain scheduled control method for the rotational speed control is proposed. Effectiveness of the method is verified by simulations. This method is differ- 
ent from conventional variable speed control in that no approximation is made in model transformation.

\section{Operation modes of DFIG System}

In general, a DFIG system has two operation modes which are described briefly below. Operation mode 1 is in the wind speed region between the cut-in wind speed and the rated wind speed. In this region, the pitch angle is fixed to 0 , and the rotational speed of wind turbine is controlled in order to get better conversion efficiency [1]. Operation mode 2 is in the wind speed region between the rated wind speed and the cut-out wind speed. The control objective is to maintain the rated power by controlling the pitch angle as well as the rotational speed of wind turbine [2].

This paper deals with the rotational speed control of DFIG system in operation mode 1 .

\section{Aerodynamic Characteristics}

Tip speed ratio, which is used to evaluate the performance of the wind turbine, is defined as

$$
\lambda=\frac{\omega \cdot R}{V}
$$

where $\omega$ is the rotational speed of wind turbine, $R$ is the turbine radius, and $V$ is the wind speed.

The power coefficient $C_{p}(\lambda)$ represents the power conversion efficiency of a wind turbine. In the case of operation mode 1 , the power and torque coefficients vary only with the tip speed ratio. The power coefficient is approximated as the following equation [3]:

$$
\left\{\begin{array}{l}
C_{p}(\lambda)=0.5176 \cdot\left(\frac{116}{\lambda_{i}}-5\right) \cdot e^{-\frac{21}{\lambda_{i}}}+0.0068 \lambda \\
\frac{1}{\lambda_{i}}=\frac{1}{\lambda}-0.035
\end{array}\right.
$$

The relationship between the power coefficient $C_{p}(\lambda)$ and torque coefficient $C_{q}(\lambda)$ is

$$
C_{q}(\lambda)=\frac{C_{p}(\lambda)}{\lambda}
$$

It can be seen from equation (2) that the maximum power coefficient is 0.48 and the optimal tip speed ratio is 8.10 , at which the wind turbine can capture the wind energy with maximum efficiency. It also can be seen from equation (2) and equation (3) that the maximum torque coefficient is 0.0647 which is achieved at the tip speed ratio of 6.76. So the optimal rotational speed for a given wind speed is

$$
\omega_{\text {opt }}=\frac{8.10}{R} \cdot V
$$

According to equation (4), the optimal rotational speed may be computed by measurement of wind speed. The maximum power point tracking may be implemented by setting the optimal rotational speed as the speed command of the wind turbine. In addition, there also exist other methods which search the optimal rotational speed by means of search algorithms. In this paper, the first method is adopted in simulation because the focus here is on the rotational speed control.

\section{Model of Wind Turbine}

The mechanical power of wind turbine is given by

$$
P_{m}=\frac{1}{2} \rho \pi R^{2} \cdot C_{p}(\lambda) \cdot V^{3}
$$

where $\rho$ is the air density. The maximum power for a given wind speed is

$$
P_{m-o p t}=K_{p} \cdot V^{3}
$$

where $K_{p}$ is determined by equation (5) with $\lambda_{\text {opt }}=8.10$ substituted into $C_{p}(\lambda)$.

Moreover, the aerodynamic torque is given by

$$
T_{m}=\frac{1}{2} \rho \pi R^{3} \cdot C_{q}(\lambda) \cdot V^{2}
$$

\section{Dynamic Model of DFIG System}

\subsection{DFIG Model}

The electric circuit configuration of DFIG is shown in Fig 2, where $u_{d s}$ and $u_{q s}$ denote the stator voltages, $u_{d r}$ and $u_{q r}$ denote the rotor voltages, $i_{d s}$ and $i_{q s}$ denote the stator currents, $i_{d r}$ and $i_{q r}$ denote the rotor voltages, $\psi_{d s}$ and $\psi_{q s}$ denote the stator fluxes and $\psi_{d r}$ and $\psi_{q r}$ denote the rotor fluxes in $d-q$ frame. In modeling the stator and rotor of DFIG, the motor convention is used.
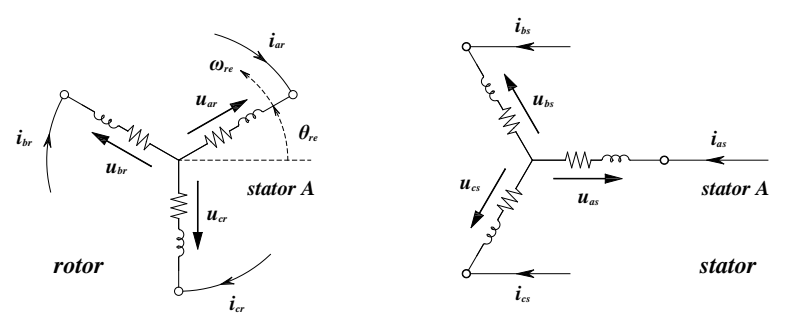

Fig. 2: Circuit configuration of DFIG.

The values of physical parameters for DFIG studied here are illustrated in table 1.

Table 1. The values of physical parameters for DFIG.

\begin{tabular}{lr}
\hline Stator resistance $R_{s}$ & $0.087 \Omega$ \\
Rotor resistance $R_{r}$ & $0.225 \Omega$ \\
Stator inductance $L_{s}$ & $84.59 \mathrm{mH}$ \\
\hline
\end{tabular}


Rotor inductance $L_{r}$

$85.71 \mathrm{mH}$

Mutual inductance $L_{m}$

$83 \mathrm{Hm}$

Rated power

$35 \mathrm{~kW}$

Rated voltages of stator and rotor

$380 \mathrm{~V}$

The equivalent circuit of DFIG in the $d$ - $q$ reference frame which rotates with synchronous speed $\omega_{1}=2 \pi f$ ( $f$ : power supply frequency) is used to set up the model equations. The voltage equations of DFIG with constant coefficients in the $d$ - $q$ reference frame are

$$
\left\{\begin{array}{l}
u_{d s}=R_{s} \cdot i_{d s}+\dot{\psi}_{d s}-\omega_{1} \cdot \psi_{q s} \\
u_{q s}=R_{s} \cdot i_{q s}+\omega_{1} \cdot \psi_{d s}+\dot{\psi}_{q s} \\
u_{d r}=R_{r} \cdot i_{d r}+\dot{\psi}_{d r}-\omega_{s} \cdot \psi_{q r} \\
u_{q r}=R_{r} \cdot i_{q r}+\omega_{s} \cdot \psi_{d r}+\dot{\psi}_{q r}
\end{array}\right.
$$

The flux linkage equations with constant coefficients in the $d$ - $q$ reference frame are

$$
\left\{\begin{array}{l}
\psi_{d s}=L_{s} \cdot i_{d s}+L_{m} \cdot i_{d r} \\
\psi_{q s}=L_{s} \cdot i_{q s}+L_{m} \cdot i_{q r} \\
\psi_{d r}=L_{m} \cdot i_{d s}+L_{r} \cdot i_{d r} \\
\psi_{q r}=L_{m} \cdot i_{q s}+L_{r} \cdot i_{q r}
\end{array}\right.
$$

The relationship between the slip frequency $\omega_{s}$ and slip $s$ is defined as

$$
\omega_{s}=\omega_{1} \cdot s=\omega_{1}-n_{p} \cdot \omega_{r m}
$$

where $n_{p}$ and $\omega_{r m}$ denote the number of pole pairs and the generator mechanical angular speed, respectively.

The equations about the electromagnetic torque (driving torque) and the reactive power at the stator terminal are

$$
\left\{\begin{array}{l}
T_{e}=n_{p} L_{m} \cdot\left(i_{q s} \cdot i_{d r}-i_{d s} \cdot i_{q r}\right) \\
Q=u_{q s} \cdot i_{d s}-u_{d s} \cdot i_{q s}
\end{array}\right.
$$

It is assumed that the stator of DFIG is connected to the constant-voltage constant frequency power supply system. To realize decoupling control, $d$ axis is aligned with the grid voltage vector, which means

$$
u_{d s}=v_{s}, u_{q s}=0
$$

after the commencement of electricity generation [4], where $v_{s}$ is the magnitude of the grid voltage vector.

Since the voltage drop across the stator resistance is sufficiently low, it is neglected and the relationship between the stator voltage and flux is approximated as

$$
v_{s} \doteq \dot{\psi}_{d s}-\omega_{1} \cdot \psi_{q s} \quad, \quad 0 \doteq \omega_{1} \cdot \psi_{d s}+\dot{\psi}_{q s}
$$

It is assumed the stator flux has reached the steady state at the starting time of electricity generation, i.e.

$$
\psi_{d s}\left(t_{c i}\right)=0, \psi_{q s}\left(t_{c i}\right)=-v_{s} / \omega_{1}
$$

So after that, there holds

$$
\psi_{d s} \doteq 0 \quad, \quad \psi_{q s} \doteq-v_{s} / \omega_{1}
$$

By substituting equation (15) back into (9), the equations of the stator and rotor currents become

$$
i_{d s} \doteq-\frac{L_{m}}{L_{s}} \cdot i_{d r} \quad, \quad i_{q s} \doteq-\frac{L_{m}}{L_{s}} \cdot i_{q r}-\frac{v_{s}}{\omega_{1} L_{s}}
$$

Further, substitution of equation (16) into (11) yields the following electromagnetic torque and the reactive power [4]:

$$
\left\{\begin{array}{l}
T_{e} \doteq-\frac{n_{p} L_{m} v_{s}}{\omega_{1} L_{s}} \cdot i_{d r} \\
Q \doteq v_{s} \cdot\left(\frac{L_{m}}{L_{s}} \cdot i_{q r}+\frac{v_{s}}{\omega_{1} L_{s}}\right)
\end{array}\right.
$$

It is easy to see that the electromagnetic torque is proportional to $i_{d r}$ and the reactive power at the stator terminal is a linear function of $i_{q r}$. Therefore, the electromagnetic torque $T_{e}$ is controlled by $i_{d r}$ and the reactive power $Q$ is controlled by $i_{q r}$. Hence, it is quite natural to use a two-stage approach:

1. Control $\omega$ and $Q$ by using $i_{d r}$ and $i_{q r}$ respectively.

2. Design current feedback loops to track the current commands computed in stage 1 .

\subsection{Drive-train Model}

The schematic diagram of drive-train system is shown in Fig 3, where $T_{l}$ is the torsional torque at low-speed shaft and $T_{g}$ is the driving torque at high-speed shaft. Since the stiffness coefficient $K_{r}$ and $K_{g}$ are sufficiently low, it is neglected.

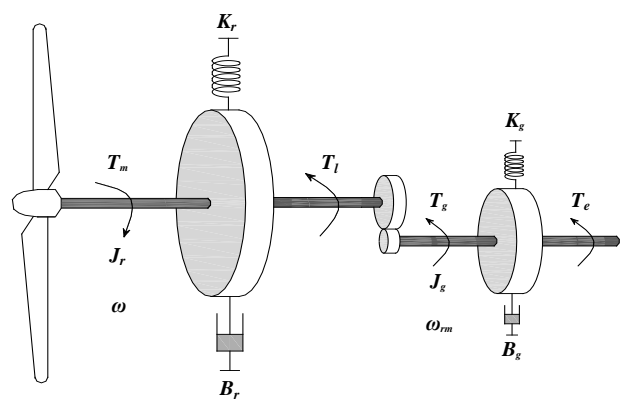

Fig. 3: Drive-train dynamics.

The values of physical parameters for drive-train system are illustrated in table 2.

Table 2. The values of physical parameters for drive-train system.

Inertia of wind turbine $J_{r}$ $63 \mathrm{~kg} \cdot \mathrm{m}^{2}$

Inertia of DFIG $J_{g}$ $4.97 \mathrm{~kg} \cdot \mathrm{m}^{2}$

Damping coefficient of wind turbine $B_{r} \quad 3.2 \mathrm{Nms} / \mathrm{rad}$ Damping coefficient of DFIG $B_{g}$ $0.8 \mathrm{Nms} / \mathrm{rad}$ 


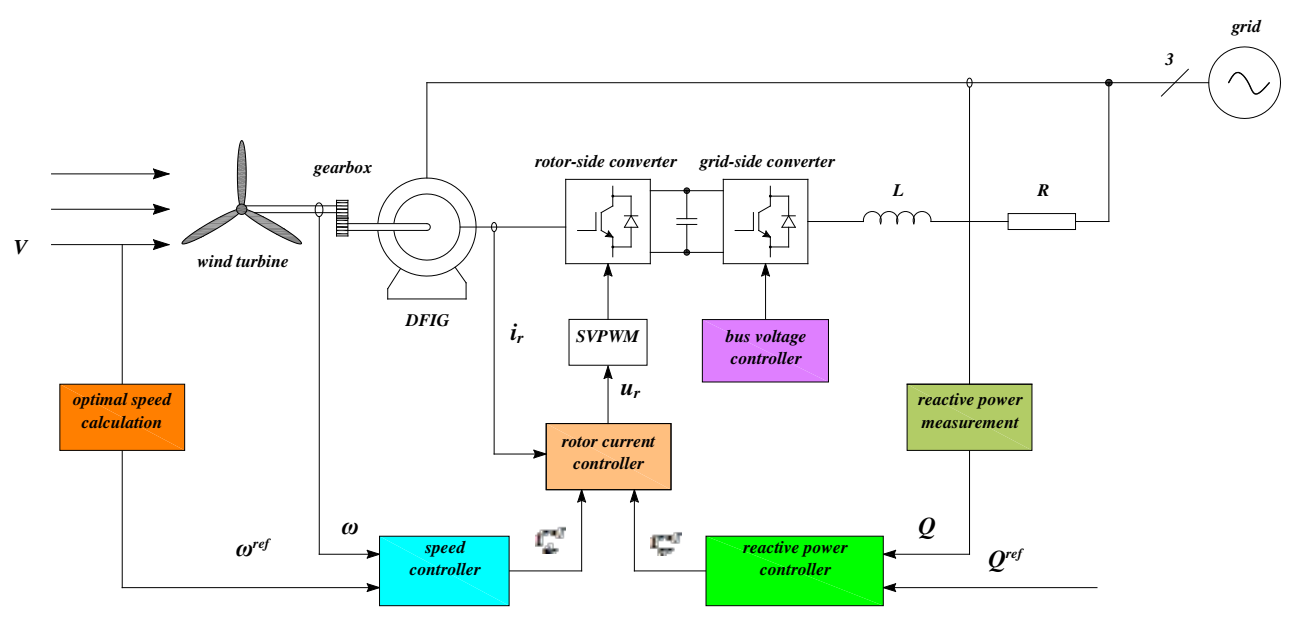

Fig. 4: Total control structure.

$$
\left\{\begin{array}{l}
T_{m}-T_{l}=J_{r} \cdot \dot{\omega}+B_{r} \cdot \omega \\
T_{g}+T_{e}=J_{g} \cdot \dot{\omega}_{r m}+B_{g} \cdot \omega_{r m}
\end{array}\right.
$$

Neglecting the power loss in gearbox, the following equation is established according to the law of conservation of energy.

$$
T_{l} \cdot \omega=T_{g} \cdot \omega_{r m}
$$

The gearbox ratio is defined by

$$
n_{g}=\frac{\omega_{r m}}{\omega}=\frac{T_{l}}{T_{g}}
$$

Substitution of equation (20) into (18) leads to the simplified model of drive train system [5].

$$
\left\{\begin{array}{l}
T_{m}+n_{g} \cdot T_{e}=J \cdot \dot{\omega}+B \cdot \omega \\
J=J_{r}+n_{g}^{2} \cdot J_{g} \quad, \quad B=B_{r}+n_{g}^{2} \cdot B_{g}
\end{array}\right.
$$

\section{Controller Design for DFIG System}

As shown in Fig.4, a double loop control configuration is adopted. In the inner loop, the current controller aims at high accuracy tracking of the reference rotor current, while in the outer loop, the rotational speed controller aims at capturing the wind energy with maximum efficiency and generates the reference rotor current. The controllers of these two loops are designed in this section.

\subsection{LPV Model for DFIG}

Based on equation (8) and (9), an LPV model equivalent to the nonlinear model of DFIG is described as

$$
G_{r c}:\left\{\begin{array}{l}
\frac{d}{d t}\left(\begin{array}{l}
i_{d s} \\
i_{q s} \\
i_{d r} \\
i_{q r}
\end{array}\right)=A_{p}\left(\omega_{r m}\right) \cdot\left(\begin{array}{l}
i_{d s} \\
i_{q s} \\
i_{d r} \\
i_{q r}
\end{array}\right)+B_{s} \cdot\left(\begin{array}{l}
u_{d s} \\
u_{q s}
\end{array}\right)+B_{r} \cdot\left(\begin{array}{l}
u_{d r} \\
u_{q r}
\end{array}\right) \\
\left(\begin{array}{l}
i_{d r} \\
i_{q r}
\end{array}\right)=C_{p} \cdot\left(\begin{array}{l}
i_{d s} \\
i_{q s} \\
i_{d r} \\
i_{q r}
\end{array}\right)
\end{array}\right.
$$

where $B_{s}$ and $B_{r}$ are constant matrices, while $A_{p}\left(\omega_{r m}\right)$ is

$$
A_{p}\left(\omega_{r m}\right)=\left(\begin{array}{cccc}
-\frac{R_{s}}{\sigma L_{s}} & \omega_{1}+\frac{L_{m}^{2} n_{p}}{\sigma L_{s} L_{r}} \cdot \omega_{r m} & \frac{R_{r} L_{m}}{\sigma L_{s} L_{r}} & \frac{L_{m} n_{p}}{\sigma L_{s}} \cdot \omega_{r m} \\
-\left(\omega_{1}+\frac{L_{m}^{2} n_{p}}{\sigma L_{s} L_{r}} \cdot \omega_{r m}\right) & -\frac{R_{s}}{\sigma L_{s}} & -\frac{L_{m} n_{p}}{\sigma L_{s}} \cdot \omega_{r m} & \frac{R_{r} L_{m}}{\sigma L_{s} L_{r}} \\
\frac{R_{s} L_{m}}{\sigma L_{s} L_{r}} & -\frac{L_{m} n_{p}}{\sigma L_{r}} \cdot \omega_{r m} & -\frac{R_{r}}{\sigma L_{r}} & \omega_{1}-\frac{n_{p}}{\sigma} \cdot \omega_{r m} \\
\frac{L_{m} n_{p}}{\sigma L_{r}} \cdot \omega_{r m} & \frac{R_{s} L_{m}}{\sigma L_{s} L_{r}} & -\omega_{1}+\frac{n_{p}}{\sigma} \cdot \omega_{r m} & -\frac{R_{r}}{\sigma L_{r}}
\end{array}\right)
$$$$
\sigma=1-\frac{L_{m}^{2}}{L_{s} L_{r}}
$$

and is affine in $\omega_{r m}$.

The size of power converter is not related to the total generator power but to the selected speed variation range. Typically a range of $\pm 40 \%$ around the synchronous speed is used [1].

For $f=50 \mathrm{~Hz}, n_{p}=3$ and $n_{g}=10$, the speed of DFIG takes value in $\omega_{r m}=20 \pi \sim 140 \pi / 3(\mathrm{rad} / \mathrm{s})$ and the speed of wind turbine takes value in $\omega=2 \pi \sim 14 \pi / 3$ ( $\mathrm{rad} / \mathrm{s})$, respectively. 


\subsection{Gain Scheduled Controller Design for Rotor Current Control Loop}

The generalized feedback system used for controller design is shown in Fig. 5 in which $K_{r c}(s)$ is the gain scheduled controller.

The controlled output is selected as the tracking error of rotor current $\left(e_{d r}, e_{q r}\right)$ and rotor voltage $\left(u_{d r}, u_{q r}\right)$, while the stator voltage is treated as a disturbance.

The closed-loop system should achieve a high tracking performance in the low frequency band since the rotor reference current is majorly a low frequency signal, so we select the weight functions $W_{s d}(s)$ and $W_{s q}(s)$ as lowpass filters. Meanwhile the weight functions $W_{u d}(s)$ and $W_{u q}(s)$ are chosen as high-pass filters.

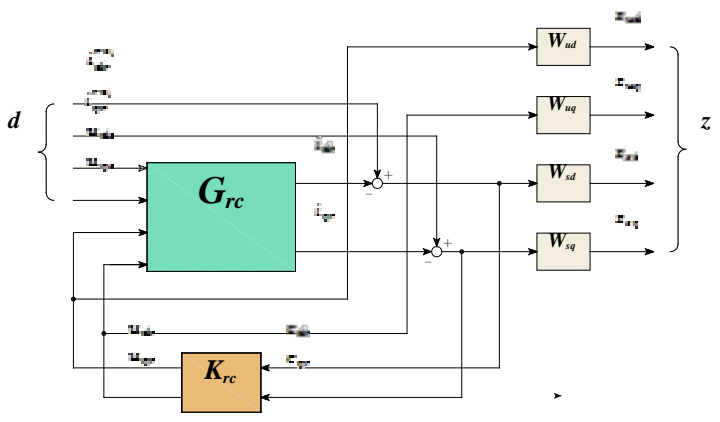

Fig. 5: Generalized plant for rotor current control design.

Weighting functions are selected as follows through trial and error

$$
\left\{\begin{array}{c}
W_{s d}(s)=W_{s q}(s)=\frac{100}{5.5 s+5} \\
W_{u d}(s)=W_{u q}(s)=\frac{0.0001 s}{s+1000}
\end{array}\right.
$$

The state-space equation of generalized plant can be written as

$$
\left\{\begin{array}{l}
\dot{x}=A\left(\omega_{r m}\right) \cdot x+B_{1} \cdot d+B_{2} \cdot u \\
z=C_{1} \cdot x+D_{11} \cdot d+D_{12} \cdot u \\
y=C_{2} \cdot x+D_{21} \cdot d
\end{array}\right.
$$

where the disturbance vector $d$, the control input vector $u$, the controlled output vector $z$ and the measured output vector $y$ are as shown in Fig.5.

An output feedback control law which is affine in $\omega_{r m}$ is considered:

$$
\left\{\begin{array}{l}
\dot{x}_{K}=\left(A_{K 0}+\omega_{r m} \cdot A_{K 1}\right) \cdot x_{K}+\left(B_{K 0}+\omega_{r m} \cdot B_{K 1}\right) \cdot y \\
u=\left(C_{K 0}+\omega_{r m} \cdot C_{K 1}\right) \cdot x_{K}+\left(D_{K 0}+\omega_{r m} \cdot D_{K 1}\right) \cdot y
\end{array}\right.
$$

where $x_{K}$ is the state vector of the controller.

An $H_{\infty}$ method is used in the design, i.e. we design an output feedback control system whose $L_{2}$ induced-gain from $d$ to $z$ is minimized. The design specification is reduced to LMIs at the maximum and minimum values of $\omega_{r m}$ in its operating range, and solved numerically [6].

The bode plots of rotor current controller for the maximum (blue lines) and minimum (red lines) values of $\omega_{r m}$ are shown in Fig.6. It can be seen from this figure that the magnitudes of frequency response vary with $\omega_{r m}$ substantially.

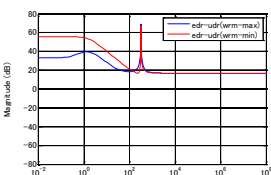

(n)
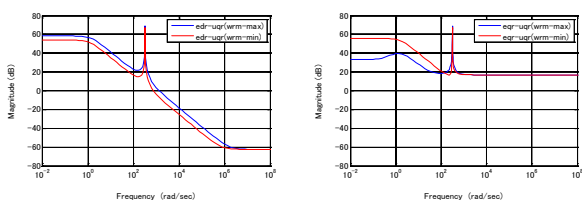

Fig. 6: Bode gain plots of rotor current controller.

\subsection{LPV Model for Drive-train System}

Substitution of equation (7) into (21) leads to an LPV model of drive train system in the operating range from the cut-in wind speed to the rated wind speed.

$$
P:\left\{\begin{array}{l}
\dot{\omega}=\left[-\frac{B}{J}+M \cdot p\right] \cdot \omega+K \cdot i_{d r} \\
y_{s}=\omega
\end{array}\right.
$$

where

$$
M=\frac{\rho \pi R^{3}}{2 J}, K=-\frac{n_{g}}{J} \cdot \frac{n_{p} L_{m} v_{s}}{\omega_{1} L_{s}}
$$

The scheduling parameter $p$ is defined as

$$
p=C_{q}(\lambda) \cdot \frac{V^{2}}{\omega}
$$

It is assumed that the wind speed is measured. So $p$ can be computed on-line and takes value in $p=0 \sim 1.03$.

\subsection{Gain Scheduled controller Design for Rotational Speed Control Loop}

The generalized feedback system shown in Fig.7 is used for rotational speed controller design.

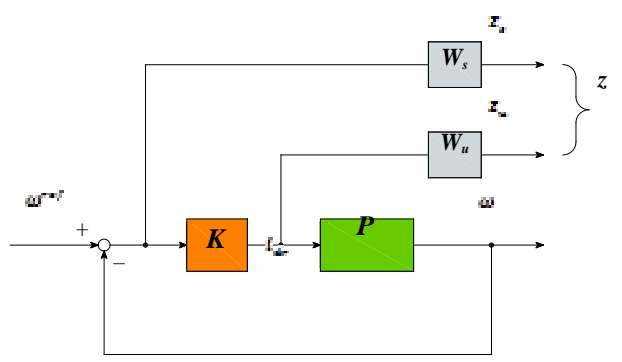

Fig. 7: Generalized plant for rotational speed controller design. 
Similarly to the rotor current control design, the controlled output is selected as the tracking error of rotational speed $\omega^{\text {ref }}$ - $\omega$ and the $d$ component of rotor current $i_{d r}$.

The weighting functions are selected as follows through trial and error

$$
\left\{\begin{array}{l}
W_{s}(s)=\frac{0.1 s+1}{2.85 s+0.001} \\
W_{u}(s)=\frac{12.4 s+31}{3 s+800}
\end{array}\right.
$$

The gain scheduled controller has the form below

$$
\left\{\begin{array}{l}
\dot{x}_{K}=\left(A_{K 0}+p \cdot A_{K 1}\right) \cdot x_{K}+\left(B_{K 0}+p \cdot B_{K 1}\right) \cdot y \\
u=\left(C_{K 0}+p \cdot C_{K 1}\right) \cdot x_{K}+\left(D_{K 0}+p \cdot D_{K 1}\right) \cdot y
\end{array}\right.
$$

The numerical design is similar to that of the rotor current loop [6].

\section{Simulation Results}

In simulations, an integrator controller

$$
K_{Q}=\frac{0.5}{s}
$$

is used as the reactive power controller. The reactive power command is set as

$$
Q^{r e f}= \begin{cases}-100 \mathrm{var} & 0 s \leq t<350 s \\ -250 \mathrm{var} & 350 s \leq t<700 s \\ -550 \mathrm{var} & 700 s \leq t \leq 1000 s\end{cases}
$$

The command of rotational speed is computed by equation (4) in which the wind speed is given in Fig.8.

Simulations results are shown in Fig. 8 Fig. 13 in the case where the wind speed input is a rapidly changing random signal.
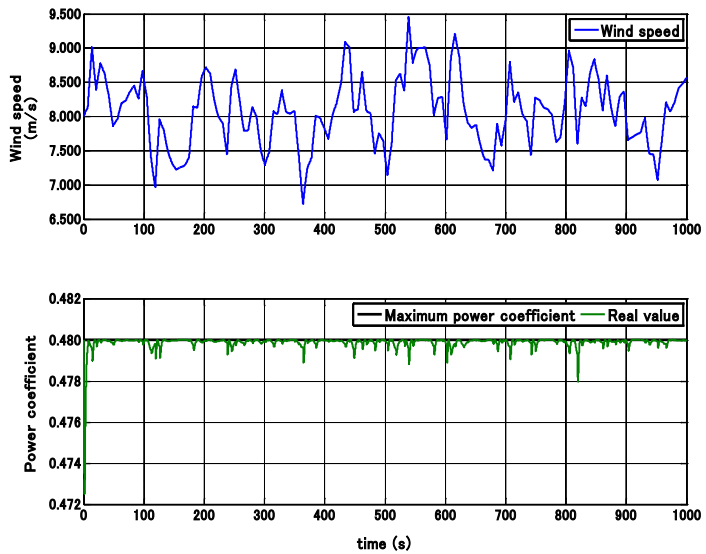

Fig. 8: Wind speed (top) and power coefficient (bottom).

As shown in Fig.8, the power coefficient is almost not influenced by the irregular variation of the wind speed and has been maintained close to its maximum value.
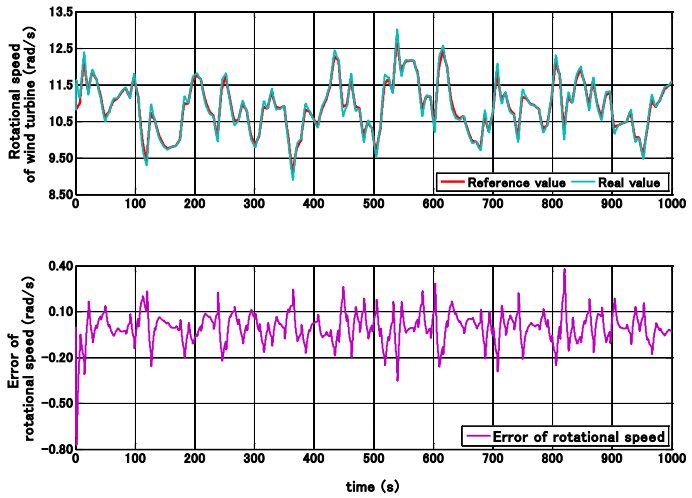

Fig. 9: Rotational speed of wind turbine (top) and tracking error of rotational speed (bottom).
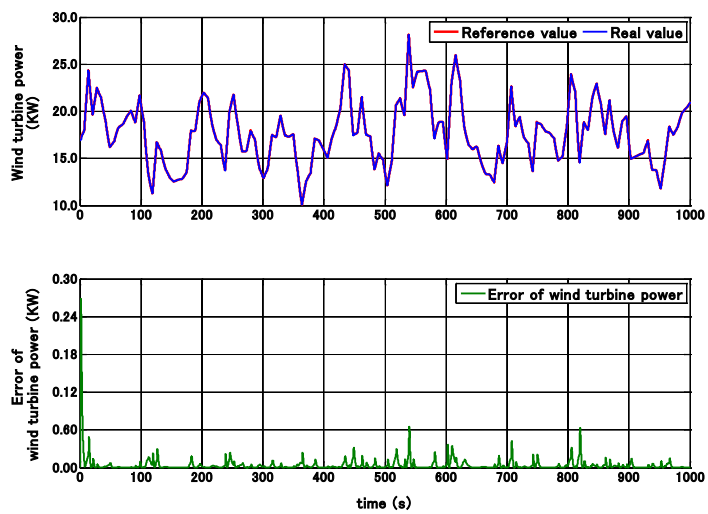

Fig. 10: Wind turbine power (top) and tracking error of wind turbine power (bottom).

It can be confirmed from Fig.9 and Fig.10 that a high tracking performance of rotational speed and the maximization of wind energy capture have been achieved.
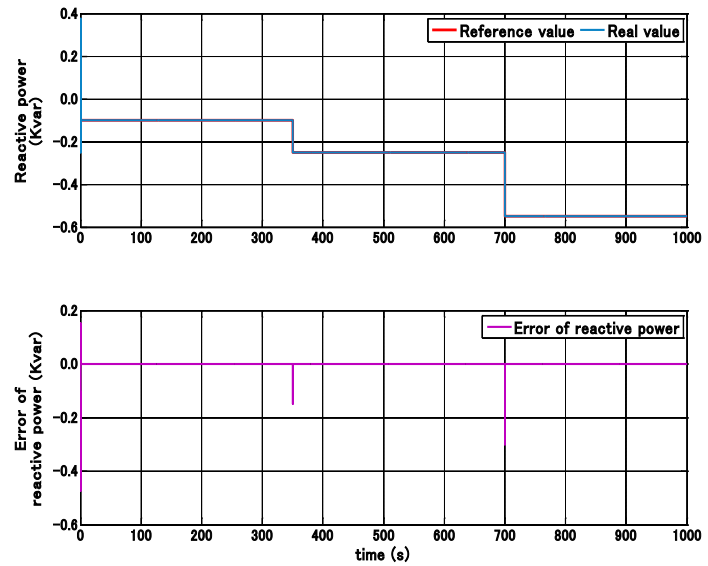

Fig.11: Reactive power (top) and tracking error of reactive power (bottom). 
The response of the reactive power is shown in Fig.11, in which it can be seen that the reactive power has achieved a high accuracy tracking of the command.
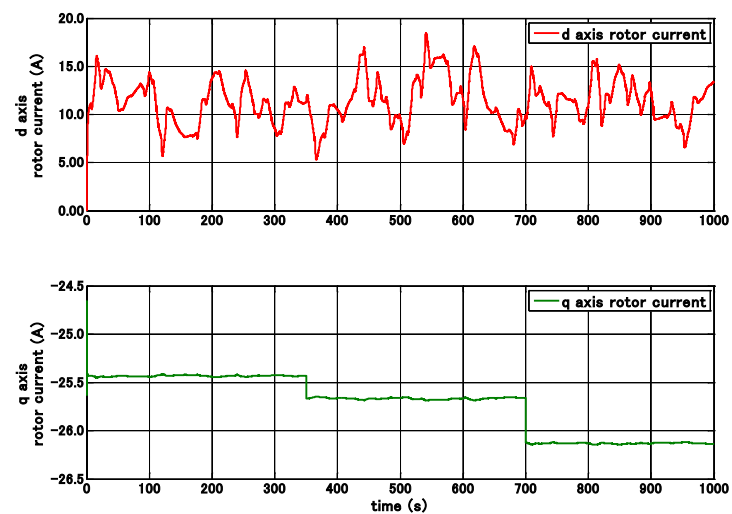

Fig.12: $d$ axis rotor current (top) and $q$ axis rotor current (bottom).

As shown in Fig.12, $i_{d r}$ varies with the wind speed while $i_{q r}$ varies with the command of reactive power. The high frequency component in the rotor currents is suppressed efficiently.
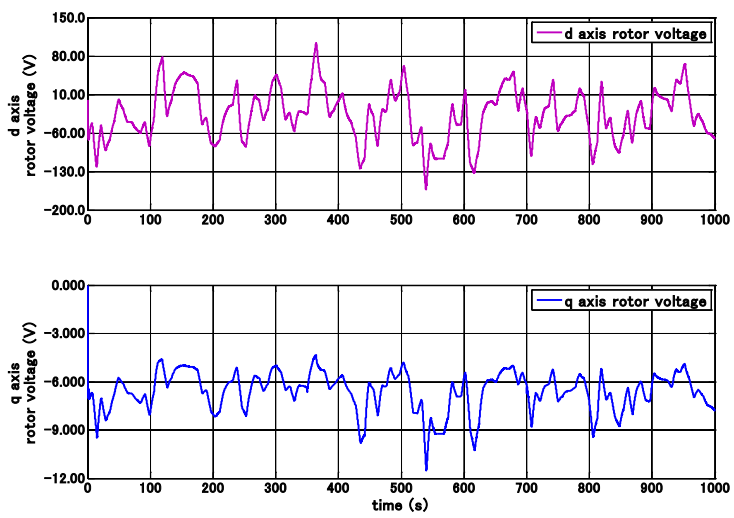

Fig.13: $d$ axis rotor voltage (top) and $q$ axis rotor voltage (bottom).

Finally, Fig.13 shows that the high frequency component in the rotor voltages is suppressed efficiently and the variation is in a reasonable range.

\section{Conclusion}

This paper has proposed a gain scheduled control method for a doubly fed induction generator driven by a wind turbine. This method is based on equivalent LPV modeling of the nonlinear DFIG system and $H_{\infty}$ optimization. It is confirmed by simulations that a quite high precision tracking control of rotor speed as well as reactive power is achieved by the proposed method.

As a future work, we plan to deal with the controller design for DFIG systems operating in mode 2 in order to maintain the rated power.

\section{REFERENCES}

[1] I.Munteanu, A.I. Bratcu, N.-A. Cutululis and E. Ceanga, "Optimal control of wind energy systems," Springer, 2008.

[2] F.D. Bianchi, H.De. Battista and R. J.Mantz, "Wind turbine control systems: principles, modeling and gain scheduling design,” Springer, 2006.

[3] A. Monroy, L. Alvarez-Icaza, "Real-time identification of wind turbine rotor power coefficient," 45th IEEE conference on decision and control, 2006, 3690-3695.

[4] N.P. Quang, A. Dittrich and A. Thieme, "Doubly-fed induction machine as generator: control algorithms with decoupling of torque and power factor," Electrical Engineering, 1997, 325-335.

[5] B. Boukhezzar and H. Siguerdidjane, "Nonlinear control of variable speed wind turbines without wind speed measurment," Proceedings of the 44th IEEE conference on decision and control, 2005, 3456-3461.

[6] P. Gahinet, A. Nemirovski, A. Laub and M. Chilali, “The LMI Control Toolbox,” The Mathworks, Inc, 1995

[7] J. Hu et al., "Direct active and reactive power regulation of DFIG using sliding-mode control approach,” IEEE Trans. on Energy Conversion, vol. 25, no. 4, pp.1028 -1038 (2010. 12)

[8] F. Wu et al., "Decentralized nonlinear control of wind turbine with doubly fed induction generator," IEEE Trans. on Power Systems, vol. 23. no. 2, pp613-621 (2008. 5)

[9] M. Rahimi and M. Parniani, "Transient performance improvement of wind turbines with doubly fed induction generators using nonlinear control strategy," IEEE Trans. on Energy Conversion, vol. 25, no. 2, pp.514-525 (2010. 6) 